\title{
Aluminium in a Cu-Mo-Al Thin Film Generated Resonantly in an Aqueous Solution using a Megahertz Rectangular Pulse Current Electrodeposition Technique
}

\author{
M. Saitou \\ University of the Ryukyus, Department of Mechanical Systems Engineering, 1 Senbaru Nishihara-cho \\ Okinawa, 903-0213, Japan. \\ E-mail: saitou@tec.u-ryukyu.ac.jp
}

doi: $10.20964 / 2017.07 .63$

Received: 12 April 2017 / Accepted: 9 May 2017 / Published: 12 June 2017

\begin{abstract}
Aluminium in a $\mathrm{Cu}-\mathrm{Mo}-\mathrm{Al}$ thin film generated on an indium tin oxide (ITO) glass substrate in an aqueous solution by a rectangular pulse current technique in a range of frequency from 0.2 to $1.5 \mathrm{MHz}$ was demonstrated. The aluminium concentration in the $\mathrm{Cu}-\mathrm{Mo}-\mathrm{Al}$ thin film measured with energy dispersive X-ray spectroscopy (EDX) was observed only in the vicinity of a resonant frequency. Several resonant frequencies existed at a certain interval in the range of the frequency. The resonant frequency spacing between the neighboring resonant frequencies became about $0.2 \mathrm{MHz}$. These experimental results are discussed from a viewpoint of energy level transition between the Fermi energy of electron in an electrode and a quantized rotational energy of a cluster of a trivalent aluminium ion and divalent molybdate ion. The maximum aluminium concentration in the $\mathrm{Cu}-\mathrm{Mo}-\mathrm{Al}$ thin film was about 6 wt. \%. X-ray diffraction (XRD) analysis showed that (111), (200), (220), and (311) planes well consistent with those of polycrystalline copper existed parallel to the ITO glass. The $\mathrm{Cu}-\mathrm{Mo}-\mathrm{Al}$ thin film is found to be an alloy comprising $\mathrm{Cu}$, Mo, and $\mathrm{Al}$. In addition, surface images of the $\mathrm{Cu}-\mathrm{Mo}-\mathrm{Al}$ thin film observed with scanning electron microscope (SEM) showed an aggregation of nano cauliflowers.
\end{abstract}

Keywords: aluminium electrodeposition; aqueous solution; megahertz; energy level transition; resonant frequency; alloy; nano cauliflower.

\section{FULL TEXT}

(C) 2017 The Authors. Published by ESG (www.electrochemsci.org). This article is an open access article distributed under the terms and conditions of the Creative Commons Attribution license (http://creativecommons.org/licenses/by/4.0/). 